applications of radioactive techniques that seem promising are the estimation of the water equivalent of deep snow by measuring the attenuation of radiation transmitted through the snow from a radioactive source immediately beneath it, the measurement of the water content of the soil by neutron absorption, and the use of natural radioactive substances produced by cosmic rays to investigate vertical diffusion and the rate of increase of carbon dioxide in the atmosphere. These subjects will be further considered by the Commission for Aerology of the World Meteorological Organization, which will meet in June 1957. As regards the assistance which meteorology can give in the use of atomic energy, the panel considered the meteorological conditions which influence the dispersal of radioactive effluents released into the atmosphere and which must be taken into account in siting and operating atomic power stations, and also considered the relationship between meteorological conditions and measured concentrations of atmospheric radioactivity. Plans were made to prepare a technical note on the subject and to maintain an up-to-date bibliography.

\section{The Radio Source in the Direction of the Galactic} Centre

A PAPER with this title, recently published by F. G. Smith, P. A. Brien and J. E. Baldwin, of the Cavendish Laboratory, Cambridge (Mon. Not. Roy. Astro. Soc., 116, 3 ; 1956), describes the results of their research on the radio source IAU $17 S 2 A$ in Sagittarius, close to the direction of the galactic centre. In spite of the fact that this radio source is one of the most intense in the sky, it has not been easy to observe owing to its peculiar location in the intense band of radiation from the galactic plane. It has been difficult to resolve both this band and also the source, using the aerial beam-widths that have previously been available, and the present paper describes the results of using aerials with high resolving power in the east-west direction at frequencies between 38 and $500 \mathrm{Mc} / \mathrm{s}$. Within that range of frequencies it is found that the flux density increases with decreasing frequency, and the brightness temperatures exceeded those expected from $\mathrm{H}$ (ii) regions. It is suggested that in this direction there is a non-thermal source of radio waves lying behind ionized hydrogen and that this source is situated in the nucleus of the Galaxy. The size of this source would be about 150 parsecs by 400 parsecs, the longer dimension lying in the plane of the Galaxy. While nuclei of dimensions as small as 20 parsecs have been observed in $S c$ galaxies, in which a high degree of turbulence has been apparent, no nuclei of such small dimensions as 150 parsecs have been reported from optical observations of $S b$ galaxies. Kwee, Muller and Westerhout have shown, however, that in our Galaxy large turbulent velocities exist in neutral hydrogen over a region several kiloparsecs across. It seems possible, therefore, that the discrete source represents a central condensation in this region.

\section{Time Zones in the U.S.S.R.}

New time zones, numbered from 2 to 12, have been officially established from March 1,1957 , on the territory of the U.S.S.R., to replace the zones fixed in 1919. These zones are in better agreement with administrative divisions, watersheds or river courses. An article by P. N. Dolgov (Priroda, No. 1, 57; 1957) includes a map of these new belts.

\section{Capital for Scientific Development}

AN inquiry has recently been carried out by the Science and Industry Committee of the Royal Society of Arts, the British Association for the Advancement of Science and the Nuffield Foundation into the possibility of speeding-up the application to industry of the results of scientific research. The report of the inquiry, by Prof. C. F. Carter, of the Department of Economics, The Queen's University, Belfast, and Prof. B. R. Williams, of the Department of Econ. omics, University College of North Staffordshire, has been published by the Oxford University Press under the title "Industry and Technical Progress". The Royal Society of Arts and the British Association have arranged a conference to discuss two of the major aspects of this report. The conference will take the form of two one-day sessions, of which the first, to be held on June 27 at the rooms of the Royal Society of Arts, will deal with "Capital for Scientific Development: the Problems of its Supply for Industry" ; while the second session, under the auspices of the British Association, will be held on July 5 at the University of Leeds (see Nature for June 1, p. 1112), and will concentrate on the supply of scientists and technologists for industry. Sir David Eccles, President of the Board of Trade, will open the Royal Society of Arts' part of the conference on June 27. The conference is open to all who are interested, without fee. Applications for tickets should be addressed to the Deputy Secretary, Royal Society of Arts, John Adam Street, Adelphi, London, W.C.2.

\section{University of Aberdeen: Blackwell Prize}

THE University of Aberdeen will award in 1959 a Blackwell Prize; this was founded in 1793 by Mrs. Barbara Blackwell, widow of Thomas Blackwell, eleventh principal of Marischal College. The value of the Prize, which is open to unrestricted competition, is $£ 60$ for the best English essay on a prescribed subject and is awarded so far as possible every alternate year. The next award will be made in 1959 for an essay on "Francis Bacon and the Modern World". Essays should be 10,000-20,000 words in length, and must be lodged with the Secretary to the University on or before January 1, 1959. Each essay must bear a motto only and be accom. panied by a sealed envelope bearing the same motto and containing the full name and address of the writer. Successful essays are placed in the University Library.

\section{Oversea Service Division: Colonial Office}

THE following appointments have recently been made in the Oversea Service Division, Colonial Office: M. A. G. Hanschell (development commissioner, St. Lucia), director of agriculture, British Honduras; T. H. Jones (assistant government chemist, Northern Nigeria), government chemist, Northern Nigeria; N. Kirby (government chemist, Jamaica), government chemist, Kenya; C. Boocock (geologist, Bechuanaland), director of Geological Surveys, Bechuanaland; J. W. Du P'reez (assistant director of Geological Surveys, Federation of Nigeria), deputy director of Geological Surveys, Federation of Nigeria; G. Turner (meteorological assistant, Northern Rhodesia), technical officer, East African Meteorological Department, East Africa High Commission; D. E. MacGregor (principal veterinary officer, Northern Nigeria), chief veterinary officer 